\title{
Consumer Judgment of Morally-Questionable Behaviors: The Relationship Between Ethical and Legal Judgments
}

\author{
Daphne Sobolev $^{1}$ D $\cdot$ Niklas Voege $^{1}$
}

Received: 7 December 2017 / Accepted: 2 February 2019 / Published online: 11 February 2019

(c) The Author(s) 2019

\begin{abstract}
Consumers' engagement in morally-questionable behaviors poses a serious threat to firms. To further the understanding of consumers' behavior, this study explores the association and conflicts between their ethical and legal judgments. In addition, it examines the way consumers' judgments depend on their mind-sets and the legal liability criterion of action (activity). In two experiments, participants were asked to judge the ethicality and legality of consumers' morally-questionable behaviors. Behavior activity and participants' mind-sets were manipulated. The results show that consumers are more likely to judge a behavior to be legal when they consider it ethical than when they consider it unethical. Nevertheless, conflicts between ethical and legal judgments are prevalent. Furthermore, ethical judgments, legal judgments, and the occurrence of conflicts between them depend on activity and on consumers' mind-sets. Finally, consumers report uncertainty about the ethicality and legality of a wide range of morally-questionable behaviors. Thus, the results paint a picture of individuals who perceive the law to be often beyond their reach or in conflict with their ethical principles. They portray both ethical and legal judgments as dynamically-changing, subjective, and context-dependent. Theoretical contribution and business applications are discussed.
\end{abstract}

Keywords Legal judgment $\cdot$ Ethical judgment $\cdot$ Mind-set

\section{Introduction}

Consumers' morally-questionable behavior is costly for firms (Bamfield 2004; Kos Koklic et al. 2016), prevalent (Blanco et al. 2008; Harris 2008; Reynolds and Harris 2005), and has been shown to have negative effects on consumers and customer-contact employees (Harris and Reynolds 2003). Furthermore, it threatens the existence of many firms (Kos Koklic et al. 2016). Therefore, it has attracted the attention of stakeholders, regulators, policy makers, consumers, and researchers (Gopal and Gupta 2010; Kos Koklic et al. 2016).

Electronic supplementary material The online version of this article (https://doi.org/10.1007/s10551-019-04124-9) contains supplementary material, which is available to authorized users.

Daphne Sobolev

d.sobolev@ucl.ac.uk

Niklas Voege

niklas.voege.15@ucl.ac.uk

1 School of Management, University College London, Gower Street, London WC1E 6BT, UK
In particular, an interest in the factors affecting consumers' morally-questionable behavior has emerged.

In line with consumer ethics research, we refer by "morally-questionable behavior" to actions, which involve deceptive legal or illegal practices, indirectly harm a seller or a firm, or result in active or passive benefits on their expense (Vitell and Muncy 1992). A wide range of drivers of consumers' morally-questionable behaviors has been identified. For instance, it has been shown that financial gains and ego revenge promote dysfunctional behavior (Daunt and Harris 2012). However, criminology theories have highlighted people's legal and moral judgments as the central determinants of their behavior (Antonaccio et al. 2017). Specifically, the situational action theory has proposed that people's actions depend on the way that they perceive their action alternatives. Hence, people's engagement in crime depends on the extent to which they judge action alternatives to be legal and moral $^{1}$ (Wikström 2006; Wikström et al. 2011). Nevertheless, consumer ethics research has predominantly focused on ethical judgments (Vitell 2003; Vitell et al. 2016) and has understudied consumers' legal judgments.

Throughout the paper, we refer by 'conflicts between ethical and legal judgments' to situations, in which consumers 
judge a behavior to be ethical but illegal, or unethical but legal. According to this definition, conflicts occur if the discrepancies between ethical and legal judgments are large enough. In contexts other than consumer ethics, business ethics research has acknowledged the distinction between people's ethical and legal judgments. It has emphasized that "ethics research that ignores the distinction between legal and ethical considerations in assessing judgment is prone to misclassification, misevaluation, and misinterpretation" (Pearce 2013, p. 498). In consumer ethics contexts, a study has revealed that a proportion of ethical consumers experience intense moral conflicts which threaten the moral coherence of their self (Carrington et al. 2015). However, the examined conflicts have been related to consumption choices (e.g., environment friendly clothes). Thus, it has not explored the nature of conflicts between consumers' ethical and legal judgments of ethically-questionable marketplace behaviors. We are unaware of studies examining such conflicts.

Consumer ethics research has provided important insights into the dependence of ethical judgment of morally-questionable behaviors on the nature of the judged behaviors. A stream of studies has revealed that consumers consider behaviors, in which the actor actively benefits on the expense of the seller, to be less ethical than behaviors, in which the actor passively benefits on the expense of the seller (Muncy and Vitell 1992). We term the variable ranging between passive behaviors and active behaviors 'activity'. Although research has established that activity affects consumers' ethical judgments (Vitell 2003), neither the effect of activity on legal judgments, nor its effect on the conflicts between ethical and legal judgments has been examined.

Consumer ethics research has also shown that ethical judgments of marketplace behaviors depend on consumers' characteristics (e.g., demographic details, beliefs, and personality traits; Vitell 2003; Vitell et al. 2016). For example, it has revealed that consumers who are more spiritual tend to be more ethical. In contexts other than ethics, consumer research has established that mind-sets significantly affect people's judgments. For instance, it has shown that when consumers develop a "which-to-buy" mind-set, they tend to buy more (Xu and Wyer 2007). The term 'mind-set' refers to a state, which is "characterized by the persistence of cognitive processes and judgmental criteria that are activated in the course of performing a task. Once activated, it generalizes to other situations, affecting responses in these situations as well" (Xu and Wyer 2007, pp. 556-557). However, the effects of consumers' mind-sets on their ethical and legal judgments and the conflicts between them have not been explored.

Accordingly, the aim of this paper is to advance the understanding of the factors affecting consumers' judgment of morally-questionable behavior. In particular, it aims at elucidating the nature of the association between consumers' ethical and legal judgments, as well as the dependence of consumers' judgments and conflicts on activity and on consumers' mind-sets. Understanding consumers' judgments enables us to develop methods to reduce consumers' engagement in unethical behavior. Furthermore, it enables us to address the literature gaps discussed above and hence make theoretical contributions.

\section{Association Between Ethical and Legal Judgments}

The notion of ethics is defined to be the set of "moral-based values that an individual or group believes are good and right in a specific situation", whereas the notion of legality is defined by a "system of rules that are created and enforced by recognized authorities" (Pearce 2013, p. 498). Throughout the paper, we use the term 'ethical judgment' to describe the process through which people determine whether a behavior is ethical. We refer by 'legal judgment' to the process through which people determine whether a behavior is legal. As people are not always familiar with the law (Pleasence and Balmer 2012; Preston-Shoot and Mckimm 2013), we suggest that determining whether a behavior is legal or not involves judgment under uncertainty (Tversky and Kahneman 1974) rather than merely recall processes.

The strength of the association between consumers' legal and ethical judgments has not been empirically studied. Furthermore, the literature about the relationship between ethical and legal judgments is fragmented and separated between three disciplines: legal philosophy, moral psychology, and consumer ethics. However, all three disciplines have portrayed ethical and legal judgments as distinct, but mutually dependent constructs.

Legal philosophers have highlighted the differences between ethical and legal judgments. Drawing on legal positivism, they have suggested that people can identify formal rules of behavior although they may not consider them moral (Raz 2012, pp. 156-157). The distinction between legal and ethical judgments is reflected also through natural law theories. Specifically, the idea that law is required to regulate the behavior of those, whose moral principles diverges from the social good (Finnis 2011, p. 125), reflects the perception that the law does not always coincide with people's moral principles. In addition, it has been theorized that ensuring compliance with law requires more social pressure than ensuring compliance with norms-based ethical rules (Ullmann-Margalit 1977). However, legal philosophers have also pointed out that there are similarities between morality and law. Both law and morality aim at protecting life and the continuity of society (La Torre 2010, p. 243). Furthermore, the legal system has been conjectured to draw its legitimacy from 
the moral principles it is based on. The similarity between morality and law suggests that people's ethical and legal judgments are likely to coincide in many cases. Similarly, legal philosophers have argued that society is well-ordered only when people endorse the rules of justice, which are enforced by the social institution (Rawls 1999, pp. 3-6). The fact that most people obey the law suggests that their legal judgments may overlap with their ethical judgments.

Moral psychology studies have demonstrated that morality develops through the internalization of law and social norms (Brady and Hart 2007; Kohlberg 1981). During childhood, the distinction between "good" and "bad" is determined by the attempt to avoid punishment and gain rewards. Adolescents often associate morality with law and social norms. This association provides adults with a reference for their moral judgments. It has been demonstrated that only a minority of adults base their moral judgment on universal justice principles (Kohlberg 1981). Thus, moral psychology theories highlight the influence of legal judgments on ethical judgments.

Business ethics research has identified discrepancies between people's ethical judgments and the law (Libby and Agnello 2000; Pearce 2013). However, it has demonstrated that most consumers agree with the statement, that if a behavior is illegal, then it is unethical (Vitell and Muncy 1992). It has also showed that behavior legality is a central consideration in consumers' ethical judgment (Vitell 2003). Following research in these three disciplines, we hypothesize that there is a positive relation between consumers' legal and ethical judgments. That is, we hypothesize that if consumers judge a behavior to be legal, then they are more likely to judge it to be ethical than they are likely to judge it to be unethical. If consumers judge a behavior to be illegal, then they are more likely to judge it to be unethical than they are likely to judge it to be ethical:

H1 Consumers' ethical and legal judgments are positively related.

\section{Effects of Activity on Ethical and Legal Judgments}

As mentioned above, we refer by 'activity' to the variable ranging on the continuum between 'passively benefiting on the expense of the seller' and 'actively benefiting on the expense of the seller' (Vitell and Muncy 1992). We say that a consumer actively benefits on the expense of others if the consumer's behavior is a causal antecedent of the harm experienced by others. A consumer passively benefits on the expense of others if the consumer's lack of behavior is an antecedent of the harm, and there is another event, or event characteristic, which is a causal antecedent of the harm (Sloman et al. 2009).

The distinction between active and passive benefits can be viewed as a special case of the distinction between 'doing' and 'allowing'. Many philosophers have debated the nature and validity of this distinction (Asscher 2007; Bennett 2003; Bradley and Stocker 2005). Studies in experimental philosophy have demonstrated that lay people distinguish between situations of 'doing harm' and 'allowing harm', and attribute greater compensatory responsibility to 'doing harm' cases than to 'allowing harm' cases (Barry et al. 2014). People perceive doing harm as less moral than allowing harm (Cushman et al. 2008). In fact, moral psychology studies have revealed that children can identify others' intentions and include them in their moral judgments (Helwig et al. 2001). Furthermore, children can distinguish between harmful behaviors and behaviors which do not involve harm (Smetana 1985). As with adults, they judge active harming to be morally worse than inactive harming (Powell et al. 2012).

Business ethics studies have established that ethical judgments of scenarios involving benefits depend on the way the benefits are obtained (Muncy and Vitell 1992; Vitell 2003). Although consumer ethics research has not differentiated between consumers' legal judgment and activity as separate variables, it has revealed that actively benefiting on the expense of others is considered more unethical than passively benefiting on the expense of others (Vitell and Paolillo 2003). For example, the active behavior 'drinking a can of soda in a supermarket without paying for it' is considered to be less ethical than the passive behavior 'observing someone shoplifting and ignoring it' (Vitell and Muncy 1992).

The effect of activity on consumers' legal judgment has not been explored. However, activity is a central determinant of criminal liability in criminal law (Husak 2010). Therefore, we expect that if consumers know whether a behavior is legal or not, then their judgment would depend on activity. In other words, we hypothesize that both ethical and legal judgments of consumers' morally-questionable behaviors depend on the extent to which the behaviors are active:

$\mathrm{H} 2 \mathrm{a}$ Actively benefitting on the expense of the seller is judged to be less ethical than passively benefitting on the expense of the seller.

$\mathrm{H} 2 \mathrm{~b}$ Actively benefitting on the expense of the seller is judged to be less legal than passively benefitting on the expense of the seller.

Because moral conflicts have been shown to have a profound influence on consumers (Carrington et al. 2015), in addition to examining the effect of activity on ethical and legal judgments, we investigate the effect of activity on 
conflicts between ethical and legal judgments. The dependence of conflicts on activity has not been studied. However, as ethical and legal judgments have been theorized to be different (Raz 2012), we conjecture that their patterns of dependence on activity are different, too. Conflicts between ethicality and legality occur if the differences between them are large enough. Thus, if the differences between the patterns of dependence of ethical and legal judgments on activity are large enough, then activity would influence the occurrence of conflicts between them. We examine this possibility empirically.

\section{Effects of Mind-Sets on Ethical and Legal Judgments}

In the context of consumers' judgment, we refer by 'mindset' to the cognitive processes which are activated when consumers approach a judgmental task. A long tradition of philosophical research has proposed that temporary experiences, which are closely related to mind-sets, affect judgment. For instance, Kant believed that emotions bias moral judgments (Pizarro 2000). Similarly, moral psychology studies have revealed that moral judgments depend on people's emotions (Cheng et al. 2013), beliefs (Walker et al. 2012), and goals (Callan et al. 2013). Furthermore, business research has established that mind-sets influence human judgments in a wide range of consumption and business contexts (Janiszewski and Wyer 2014; Tsalikis 2015; Xu and Wyer 2007). Therefore, we hypothesize that consumers' ethical judgments of morally-questionable behaviors depend on their mind-sets.

No previous study has examined the effect of consumers' mind-sets on their legal judgment. However, perceiving legality judgments to be judgments under uncertainty (Tversky and Kahneman 1974), we conjecture that they are susceptible to human judgment biases as ethics judgments are. Therefore, we hypothesize that consumers' mind-sets influence also their legal judgments:

H3a Mind-sets affect consumers' ethical judgments.

H3b Mind-sets affect consumers' legal judgments.

As with activity, in addition to examining the effect of consumers' mind-sets on their ethical and legal judgments, we explore the dependence of conflicts between ethical and legal judgments on consumers' mind-sets. The dependence of conflicts on mind-sets has not been studied. However, as ethical and legal judgements are different (Raz 2012), we expect that there are differences between their patterns of dependence on mind-sets, too. If these differences are large enough, mind-sets would influence the occurrence of conflicts between ethical and legal judgments. We explore this conjecture empirically.

We were primarily interested in three mind-sets: aggression, politeness, and awareness to legal punishment. Research has demonstrated that aggression affects people's judgment and behavior (Carlson et al. 1990; Daunt and Harris 2012; Todorov and Bargh 2002) due to its influence on the way they interpret situations (Reynolds and Harris 2009). People, in whom aggression mind-set is induced, tend to judge unethical behaviors leniently (Tsalikis 2015). People with high levels of aggression (as a personality trait) exhibit low sensitivity to ethical issues, too (Rallapalli et al. 1994). Therefore, we expected aggression mind-set to affect consumers' judgments.

Past research on the effect of politeness cues on people's behavior and perceptions has yielded inconclusive results: although inducing politeness in people had a positive effect on their behavior (Bargh et al. 1996), it did not lead to improved sensitivity to business-related ethical issues (Tsalikis 2015). We chose to study politeness to examine the effect of a positive mind-set on ethical and legal judgments.

The effect of awareness to legal punishment on ethical or legal judgment has not been studied. However, ethical judgments have been found to depend on normative punishments (e.g., being chastised by a store manager or by co-workers; Vitell et al. 2001). Furthermore, it has been theorized that decisions about engagement in morally-questionable behaviors depend on the perception that punishment is probable (Robinson and Darley 2004). Because people often use the availability heuristic for probability judgments (Tversky and Kahneman 1973), raising consumer awareness to legal punishment is likely to increase the perceived probability of being punished. Thus, we explored the influence of awareness to legal punishment on consumers' ethical and moral judgments.

\section{Contribution to Business Ethics Research}

This study contributes to business ethics research insights into the way consumers make ethical and legal judgments. First, it theorizes and empirically demonstrates that ethical and legal judgments are positively associated and significantly affected by the activity of the judged behavior and consumers' mind-sets. In addition, it empirically demonstrates that the occurrence of conflicts between ethical and legal judgments depends on the activity of the judged behaviors and consumers' mind-sets.

Second, this study provides business ethics research with new perspectives on consumer ethics. Consumer ethics research has tended to overlook the relationship between ethical judgment and other judgments. However, situations which require ethical judgments often require 
also other justice-related judgments. This study is the first to provide information about the relationship between ethical and legal judgments. Therefore, it provides consumer ethics research with a broad, holistic perspective on consumers' judgment. This study is also the first to systematically explore conflicts between consumers' ethical and legal judgments. Thus, it provides insights into the complexity of consumers' judgments. Furthermore, examining the effect of mind-sets on consumers' judgments, it provides consumer ethics research with a context-dependent perspective.

Third, by showing that consumers' legal judgments are susceptible to mind-sets and that consumers are often unfamiliar with the law, this study conceptualizes legal judgment as judgment under uncertainty (Tversky and Kahneman 1974). Furthermore, it emphasizes the importance of the study of legal judgment. A few business ethics studies have examined the effect of scenarios' legality on consumers' ethics perceptions (Vitell 2003; Vitell and Paolillo 2003). Although these studies have yielded important results, they have not differentiated between the law and consumers' legal judgments. Thus, previous results about the dependence of ethical judgments on law may not reflect consumers' judgments.

Finally, business ethics research has tended to focus on the dependence of consumers' ethical judgments on relatively stable, individual factors, which are impossible or difficult to change (e.g., gender, personality, religiosity, spirituality, moral identity, culture, and nationality; Vitell 2003; Vitell and Paolillo 2003; Vitell at al. 2016). Thus, consumer ethics theories tended to be descriptive. Consistently with research on management ethics (Tsalikis 2015), this study shows that consumers' ethical judgments can be influenced by external manipulations. This observation suggests that environmental cues and educational efforts may increase consumers' sensitivity to ethical issues. By highlighting this new application field, we extend consumer ethics research to the development of dynamical theories. Additional theoretical contributions are discussed in Appendix A.

\section{Experiment 1}

Experiment 1 was designed to test hypotheses $\mathrm{H} 1, \mathrm{H} 2 \mathrm{a}$ and $\mathrm{H} 2 \mathrm{~b}$. In addition, it examined the prevalence of conflicts between consumers' ethical and legal judgments and their dependence on activity. Participants were asked to judge the ethicality and legality of morally-questionable consumer and internet behaviors. Activity of the presented behaviors was manipulated.

\section{Method}

\section{Participants}

Seventy-seven people acted as participants. They were recruited in the UK, however, had diverse nationalities (including British, French, Italian, Dutch, Belgian, Greek, Polish, Romanian, American, Brazilian, Singaporean, Malaysian, Indian, and Moroccan nationalities). Sixty of the participants were undergraduate or postgraduate students. Two participants (2.6\%) were excluded due to outlier analysis (based on Cook's distance method; Cook 1977), leaving 75 participants for the analysis (44 women; age mean $=22.27$ years; age $s t d=8.64$ years).

The participants were recruited by students. Each student recruited seven participants. The students were instructed to ask the participants, whom they recruited, to complete the given task (individually) in their presence. Neither the experimenters nor the participants were told what the hypotheses were. Therefore, it was a double-blind procedure.

\section{Materials}

We were interested in testing the hypotheses on a representative sample of consumer morally-questionable scenarios. Therefore, we employed two standardized questionnaires. Questionnaire 1 was based on the 27-item consumer ethics questionnaire of Muncy and Vitell (1992). It includes items such as "Returning damaged merchandise when the damage is your own fault". The questionnaire is considered representative of the breadth of ethical scenarios faced by consumers (Muncy and Vitell 1992). However, due to technological advances, we updated or omitted a few items. For example, the original item "Recording an album instead of buying it" was replaced by "Copying a music CD instead of buying it". Twenty-five items were included in questionnaire 1.

In questionnaire 1, five items described people actively benefiting at the expense of others, four items described people passively benefiting at the expense of others, five items described deceptive practices, and five items described situations which involved no harm (Muncy and Vitell 1992). Six items from the list 'Statements that did not load strongly on any factor' were chosen to mask the purpose of the study.

Questionnaire 2 was based on the internet-ethics questionnaire of Freestone and Mitchell (2004). Some of the items in this questionnaire referred to consumer ethics, e.g., "Using credit card numbers that you haven't stolen but have "discovered" yourself, e.g., from websites". The questionnaire contained items referring to other internet-related behaviors, too, e.g., hacking. Twenty-two of the 23 items in the questionnaire of Freestone and Mitchell (2004) were chosen. One item was omitted and three items were updated. 
For instance, the item "Downloading music files from the internet for free, e.g., Napster sites or similar" was replaced by "Downloading music files from the internet for free, e.g., Pirate Bay sites or similar."

To reduce order effects, the order of the questions in each of the questionnaires was randomized (with respect to the original questionnaires) and then counterbalanced. That resulted in two versions of each questionnaire. Each participant was given one of the versions of questionnaire 1 and one of the versions of questionnaire 2 .

\section{Design}

The experiment had a within-participant design with respect to the variable 'activity'. Item's activity was manipulated in questionnaire 1 according to the classification of Muncy and Vitell (1992). In particular, the questionnaire included items relating to "passively benefiting on the expense of the seller' (four items in questionnaire 1) and 'actively benefiting on the expense of the seller' (five items in questionnaire 1; Muncy and Vitell 1992). Questionnaires 1 and 2 were used to examine correlations between the variables.

\section{Procedure}

For each item, participants were asked to give two responses: an ethical judgement and a legal judgment. The instructions were: "The following questionnaire includes two sets of items (a total of 47 statements), describing actions in different situations. Please rate the extent to which you perceive each action as ethical and legal on a 5-point scale." For each ethicality judgment, participants' answers were given on a Likert scale ranging between "Strongly believe that it is NOT ethical" (1) to "Strongly believe that it is ethical" (5). The option ' 3 ' represented "Do not have an opinion". Legality was judged using a Likert scale ranging between "Very confident that it is illegal" (1) and "Very confident that it is legal" (5). The answer '3' represented "Do not know".

\section{Results}

\section{Association Between Ethical and Legal Judgments}

To test hypothesis H1 (consumers' ethical and legal judgments are positively related), the correlations between participants' ethical and legal judgments were calculated. (Throughout the analysis we pooled together the results of both versions of the questionnaires, counterbalancing for order effects). For each of these questionnaires, the correlation between participants' ethical and legal judgments was significant and positive (questionnaire 1: $r=0.47, p<0.001$; questionnaire 2: $r=0.59, p<0.001)$. These results supported hypothesis $\mathrm{H} 1$.

\section{Dependence of Legal and Ethical Judgments on Activity}

To test hypotheses $\mathrm{H} 2 \mathrm{a}$ (actively benefitting on the expense of the seller is judged to be less ethical than passively benefitting on the expense of the seller) and $\mathrm{H} 2 \mathrm{~b}$ (actively benefitting on the expense of the seller is judged to be less legal than passively benefitting on the expense of the seller), we extracted participants' responses to items from the categories 'passively benefiting on the expense of the seller', and 'actively benefiting on the expense of the seller' (Muncy and Vitell 1992). ANOVAs on participants' ethical and legal judgments, using activity as a within-participant variable, revealed that the effect of activity on ethical judgments was significant $(F(1,673)=22.00 ; p<0.01)$. Passively benefitting on the expense of the seller was judged to be more ethical (mean ethics ratings $=1.94, \mathrm{std}=1.08$ ) than actively benefitting on the expense of the seller (mean ethics ratings $=1.60$, std $=0.88$ ). However, the effect of activity on legal judgments was statistically insignificant. Thus, the results supported hypothesis $\mathrm{H} 2 \mathrm{a}$, but did not provide sufficient evidence to support hypothesis $\mathrm{H} 2 \mathrm{~b}$.

\section{Prevalence of Conflicts Between Ethical and Legal Judgments}

We were interested in two types of conflicts: conflicts of type I, in which a behavior is judged to be unethical but legal, and conflicts of type II, in which a behavior is judged to be ethical but illegal. Operationally, conflicts of type I were defined as cases, in which ethical judgments were less than three (the central option in the Likert scale used) and legal judgments were greater than three. In conflicts of type II, ethical judgments were greater than three and legal judgments were less than three.

Descriptive statistics of the mean percentage of conflicts are given in Table 1. Table 1 shows also the results of t-tests, comparing the mean percentage of conflicts of each type to zero. As the table shows, for questionnaire 1 , items were considered unethical but legal in $13.22 \%$ of all responses, and ethical but illegal in $4.05 \%$ of all responses. The average number of conflicts of both types per participant was significantly different from 0 (Questionnaire 1: $\mathrm{t}(74)=10.01$, $p<0.01$; questionnaire $2: t(74)=6.45, p<0.01)$. In questionnaire 1 , the items which were most frequently rated as illegal but ethical were: "Reporting a lost item as "stolen" to an insurance company to collect the money" and "Copying a music CD instead of buying it". Lower percentages of conflicts between ethical and legal judgments were obtained for questionnaire 2 . As the questionnaires are considered to represent the breadth of consumer ethical issues, we conclude that it is likely that consumers experience conflicts between their ethical and legal judgments. 
Table 1 Percentages of participants' responses, which involved conflicts between ethical and legal judgments, and the results of $t$-tests, comparing these percentages to zero

\begin{tabular}{llll}
\hline Conflict type & Questionnaire & Percentage of conflicts & $T$-test results \\
\hline Type I (unethical but legal behavior) & 1 (Consumer ethics) & Mean $=13.22 \%, \operatorname{std}=0.11$ & $t(74)=10.01^{* *}$ \\
& 2 (Internet ethics) & Mean $=5.03 \%, \operatorname{std}=0.07$ & $t(74)=6.66^{* *}$ \\
Type II (ethical but illegal behavior) & 1 (Consumer ethics) & Mean $=4.05 \%, \operatorname{std}=0.05$ & $t(74)=6.45^{* *}$ \\
& 2 (Internet ethics) & Mean $=2.06 \%$, std $=0.03$ & $t(74)=5.30^{* *}$ \\
\hline
\end{tabular}

We denote by $* *$ statistical significance at the 0.01 level

\section{Dependence of Conflicts Between Legal and Ethical Judgments on Activity}

We were interested in the dependence of conflicts of type I and II on activity. In addition, we examined cases in which ethical judgments did not conflict with legal judgments. In these cases, ethical and legal judgments were greater than three, or ethical and legal judgments were less than three. For the analysis, we used the percentage of participants' responses on the items, which referred to each of these cases.

ANOVA on the percentage of participants' responses corresponding to each of the cases, using the variable 'activity' as a within-participant variable, showed that the percentage of conflicts of type II was lower when items referred to active benefits ( mean $=0.02$, std $=0.08$ ) than when items referred to passive benefits (mean $=0.06$, std $=0.14 ; F(1$, $74)=9.96, p=0.002$, partial $\eta^{2}=0.12$ ). No other significant effects were found. Therefore, the results showed that occurrence of conflicts depends on activity.

\section{Uncertainty in Participants' Responses}

As a measure of participants' uncertainty, for each participant, we extracted the percentage of items for which the participant chose the answer "Do not know" or "Do not have an opinion" (answer ' 3 '). Analysis showed that for questionnaire 1, participants chose this answer in 20.85\% of their legal judgments and $17.91 \%$ of their ethical judgments. Answering questionnaire 2, this option was chosen in $12.61 \%$ of their legal judgments and $12.36 \%$ of their ethical judgments. These results were significantly greater than zero (questionnaire 1: $t(74)>12.16, p<0.01$; questionnaire 2: $t$ (74) $>10.41, p<0.01)$. Although, to a certain extent, these results may reflect participants' response biases (Randall and Fernandes 1991), they suggest that people are often unable to make ethicality and legality judgments.

\section{Variability of Participants' Responses}

As a proxy for consumer disagreement about legal and ethical issues, we extracted the standard deviation of participants' responses. We found that the standard deviation of participants' ethical judgments was greater than $27 \%$ of the given range (questionnaire 1 : mean $=2.36$, std $=1.32$,
$1.32 / 4=0.33 ;$ questionnaire $2:$ mean $=1.65$, std $=1.07$, $1.07 / 4=0.27$ ). The standard deviation of participants' legal judgments was greater than $30 \%$ of the given range (questionnaire 1 : mean $=2.75$, std $=1.47,1.47 / 4=0.37$; questionnaire 2 : mean $=1.81$, std $=1.27,1.27 / 4=0.31$ ).

\section{Experiment 2}

Experiment 2 was designed to investigate the robustness of Hypotheses H1, H2a and H2b with respect to consumers' mind-sets, and to test hypotheses $\mathrm{H} 3 \mathrm{a}$ and $\mathrm{H} 3 \mathrm{~b}$. In addition, we examined the prevalence of conflicts between consumers' ethical and legal judgments and their dependence on consumers' mind-sets. Priming procedures were used to induce in the participant's aggression, politeness, or awareness to legal punishment mind-sets. Subsequently, participants were asked to complete the judgmental tasks employed in Experiment 1 .

\section{Method}

\section{Participants}

Participants were recruited as in Experiment 1. Sampling aimed at obtaining a wide section of young adults. Participants had diverse academic and professional fields (e.g., management, economics, engineering, social sciences, and medicine) and educational levels (high school students, undergraduate students, postgraduate students, and professionals).

The initial sample included 225 participants, of whom $11(4.89 \%)$ were excluded after an outlier analysis (based on Cook's distance method; Cook 1977). Thus, our results are based on the answers of 214 participants (118 women; age mean $=20.41$ years; age $s t d=5.24$ years). There were 71 participants in the aggression-priming condition, 73 participants in the politeness-priming condition, and 70 participants in the awareness to legal punishment condition. The choice of sample size was based on the suggestion to have more than 50 participants per condition for adequate statistical power (Simmons et al. 2013). 


\section{Materials}

Priming research has shown that mind-sets can be activated through priming procedures (Janiszewski and Wyer 2014), including sentence unscrambling tasks (Tsalikis 2015). Thus, we employed sentence unscrambling tasks to induce aggression, politeness, and awareness to legal punishment mind-sets in the participants. In all experimental conditions, participants were presented with a list of 14 series of five words. For each series, participants were asked to circle four words which make a complete sentence. Each word series contained target words which were relevant to the priming condition. For example, a word series given in the aggression condition was: "he aggressively spoke stared yesterday", and a word series given in the politeness condition was: "they showed respect always usual". For the aggression and politeness conditions, the task was as in Tsalikis (2015). For the awareness to legal punishment condition, we modified the task, so that the unscrambled sentences described negative legal consequences of breaking the law. For instance, one of the word series given in this condition was: "arrest she under is always" (see Appendix B).

\section{Design}

The experiment had a three (mind-set: aggression, politeness, or awareness to legal punishment) by two (questionnaire: questionnaire 1 or questionnaire 2) by two (type of judgment: ethicality or legality) by two (order of questions) design, in which mind-set and question order were betweenparticipant variables, and questionnaire and type of judgment were within-participant variables. As the hypotheses were neither revealed to the experimenters nor to the participants, it was a double-blind experiment.

\section{Procedure}

Participants were assigned to one of three mind-set conditions: aggression, politeness, or awareness to legal punishment. Following the mind-set priming task, all participants were asked to fill in the questionnaires employed in Experiment 1 (questionnaire 1 and questionnaire 2).

\section{Results}

\section{Correlations Between Ethical and Legal Judgments}

To investigate the robustness of hypothesis H1 (consumers' ethical and legal judgments are positively related), we calculated the correlations between participants' ethical and legal judgments in each of the mind-set conditions. The results are presented in Table 2 . In all mind-set conditions, the correlation between ethical and legal judgments was significant (questionnaire 1: $0.38<r<0.48, p<0.001$; questionnaire 2: $0.52<r<0.55, p<0.001)$. These results suggest that hypothesis $\mathrm{H} 1$ is robust over different mind-sets.

\section{Dependence of Ethical and Legal Judgments on Activity}

To further our understanding of hypothesis H2a (actively benefitting on the expense of the seller is judged to be less ethical than passively benefitting on the expense of the seller) and $\mathrm{H} 2 \mathrm{~b}$ (actively benefitting on the expense of the seller is judged to be less legal than passively benefitting on the expense of the seller), for each of the conditions of Experiment 2, we carried out one-way ANOVAs on participants' ethical and legal judgments using activity as a withinparticipant variable. As in the analysis of Experiment 1, we used only items referring to the categories 'passively benefiting on the expense of the seller', and 'actively benefiting on the expense of the seller' from questionnaire 1 (Muncy and Vitell 1992). The results are presented in Table 3. The effects of activity on ethical and legal judgments were significant in all conditions. Thus, the results supported hypotheses $\mathrm{H} 2 \mathrm{a}$ and $\mathrm{H} 2 \mathrm{~b}$ over the examined mind-sets.

\section{Dependence of Ethical and Legal Judgments on Mind-Sets}

To test hypotheses H3a (mind-sets affect consumers' ethical judgments) and 3ba (mind-sets affect consumers' legal judgments), we carried out a two-way repeated measures ANOVAs on participants' ethical and legal judgments, using as variables mind-set (aggression, politeness, or awareness to legal punishment), and questionnaire (questionnaire 1 or questionnaire 2). For the ANOVA on ethical judgments, sphericity assumption was violated for the variable 'mindset'. We report the results of Huynh-Feldt tests here and
Table 2 Correlations between participants' ethical and legal judgments

\begin{tabular}{llll}
\hline Questionnaire & Condition & \\
\cline { 2 - 4 } & Aggression & Politeness & $\begin{array}{l}\text { Awareness to } \\
\text { legal punishment }\end{array}$ \\
\hline 1 (Consumer ethics) & $0.47^{* *}(N=1775)$ & $0.48^{* *}(N=1825)$ & $0.38^{* *}(N=1750)$ \\
2 (Internet ethics) & $0.55^{* *}(N=1562)$ & $0.53^{* *}(N=1606)$ & $0.52^{* *}(N=1540)$ \\
\hline
\end{tabular}

We denote by $* *$ statistical significance at the 0.01 level 
Table 3 Effects of activity on ethical and legal judgments

\begin{tabular}{llll}
\hline Judgment type & Condition & \\
\cline { 2 - 4 } & Aggression & Politeness & Awareness to legal punishment \\
\hline Ethical judgments & $F(1,637)=15.59^{* *}$ & $F(1,655)=12.38^{* *}$ & $F(1,628)=24.20^{* *}$ \\
Legal judgments & $F(1,637)=9.11^{* *}$ & $F(1,655)=4.53^{*}$ & $F(1,628)=44.81^{* *}$ \\
\hline
\end{tabular}

We denote by $*$ statistical significance at the 0.05 level and by ** significance at the 0.01 level whenever sphericity assumption is violated. Both variables had significant effects on participants' ethical judgments (mind-set: $F(1.99,3065.31)=45.61, p<0.001$, partial $\eta^{2}=0.03$; questionnaire: $F(1,1539)=470.56, p<0.01$, partial $\eta^{2}=0.23$ ). For the ANOVA on legal judgments, sphericity assumption was violated for the variable 'mind-set'. Both variables had significant effects on participants' legal judgments (mind-set: $F(1.98,3045.28)=4.89, p=0.008$, partial $\eta^{2}=0.003$; questionnaire: $F(1,1539)=862.34$, $p<0.01$, partial $\eta^{2}=0.36$ ). As mind-set had a significant effect on ethical and legal judgments, the results supported hypotheses $\mathrm{H} 3 \mathrm{a}$ and $\mathrm{H} 3 \mathrm{a}$.

\section{Effects of Specific Mind-Sets on Ethical and Legal Judgments}

To further our understanding of the effects of mind-sets on ethical and legal judgments, we compared participants' judgments in each of the experimental conditions to their judgments in the other conditions. For questionnaire 1, ethical judgments in the aggression condition (mean $=2.76$, std $=1.43)$ were significantly greater than in the politeness condition $($ mean $=2.37$, $\operatorname{std}=1.35 ; t(1774)=8.98$; $p<0.001)$ and in the awareness to legal punishment condition $($ mean $=2.38$, std $=1.36 ; t(1749)=8.92 ; p<0.001)$. No other significant differences between ethical judgments were found. Similarly, for questionnaire 2, ethical judgments in the aggression condition $($ mean $=1.91, \mathrm{std}=1.27)$ were significantly greater than in the politeness condition $($ mean $=1.76, \operatorname{std}=1.16 ; t(1561)=3.60 ; p<0.001)$ and in the awareness to legal punishment condition (mean $=1.83$, $\operatorname{std}=1.21 ; t(1539)=2.30 ; p=0.022)$. No other significant differences were found.

For questionnaire 1, legal judgments in the politeness condition (mean $=2.72$, std $=1.48$ ) were significantly lower than in the aggression condition (mean $=2.85$, $\operatorname{std}=1.52 ; t(1774)=3.10 ; p=0.002)$ and in the awareness to legal punishment condition $($ mean $=2.84, \mathrm{std}=1.53 ; t$ $(1749)=2.72 ; p=0.007)$. No other significant differences between the experimental conditions were found for questionnaire 1 or 2 . These results are presented in Figs. 1 and
Fig. 1 Mean ethicality judgments for questionnaires 1 (white bars) and 2 (gray bars) in each experimental condition. Dashed lines represent statistical significance at the 0.05 level

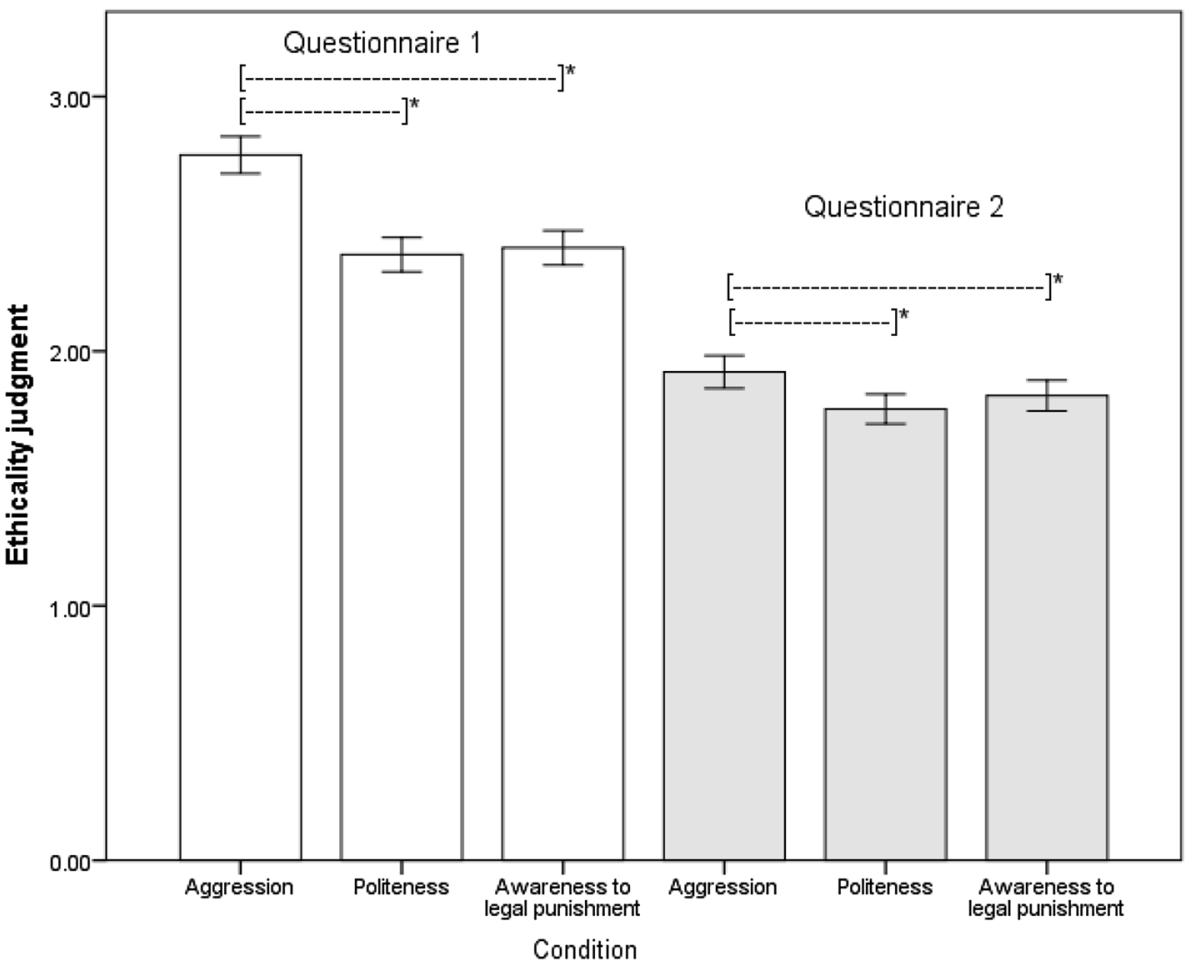


Fig. 2 Mean legality judgments for questionnaire 1 in each experimental condition. Dashed lines represent statistical significance at the 0.05 level

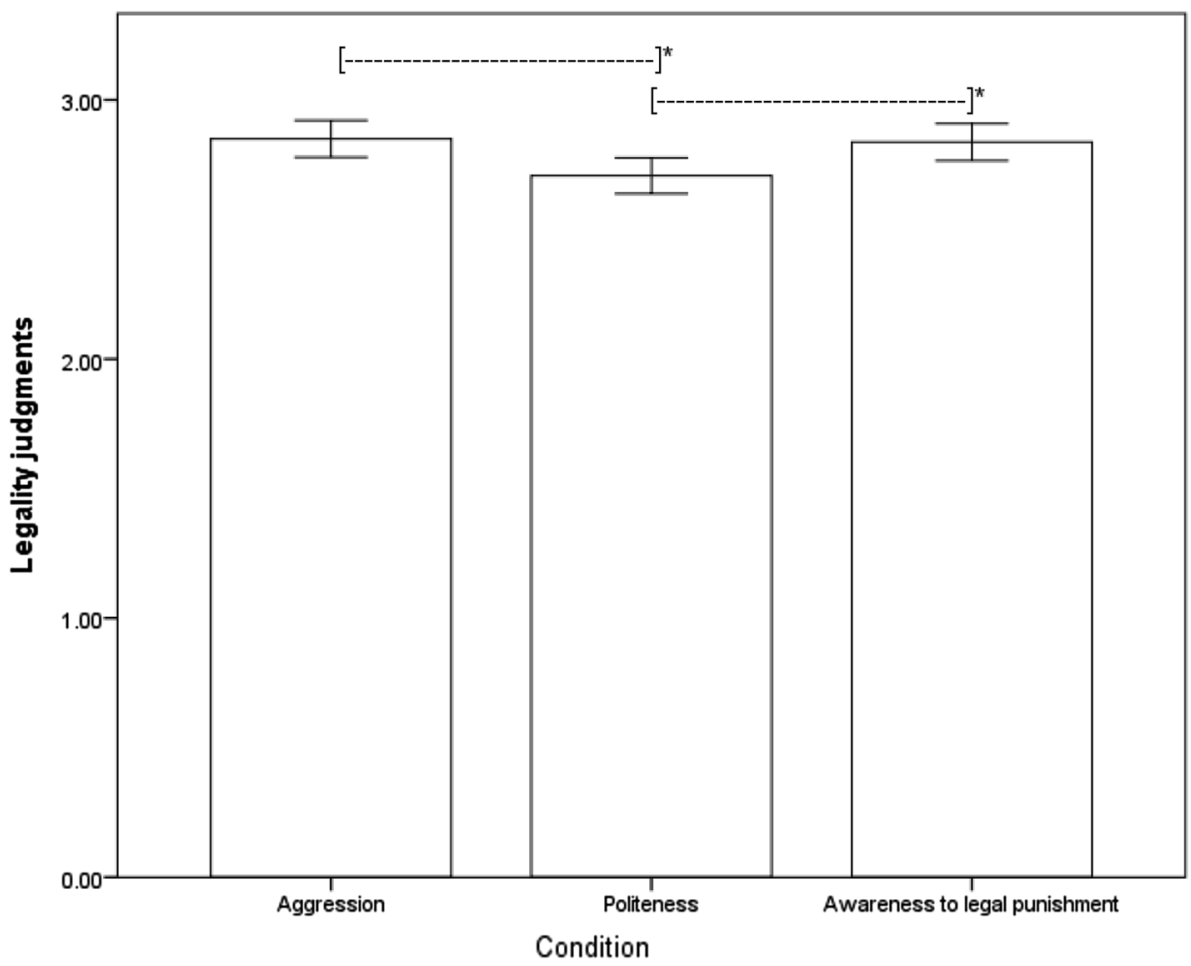

2. We conclude that aggression mind-set decreases consumers' sensitivity to ethicality and legality.

\section{Prevalence of Conflicts Between Ethical and Legal Judgments}

We extracted the percentages of conflicts of type I and type II for each participant in each condition. Descriptive statistics of the mean percentage of conflicts are presented in Table 4 . Table 4 shows also the results of $t$-tests comparing the means of the percentages of the conflicts of each type, which each participant experienced, to zero. The results reveal that in all conditions, conflicts between ethics and legal judgments occurred. The percentages of conflicting responses were significantly different from zero.

\section{Dependence of Conflicts Between Ethical and Legal Judgments on Mind-Sets}

To examine the effect of mind-sets on the occurrence of conflicts between ethical and legal judgments, for each questionnaire and each conflict type, we carried out an ANOVA
Table 4 Percentage of participants' responses, which involved conflicts between ethicality and legality judgments, and the results of $t$-tests, comparing them to zero

\begin{tabular}{|c|c|c|c|c|}
\hline \multirow[t]{2}{*}{ Conflict type } & \multirow[t]{2}{*}{ Questionnaire } & \multicolumn{3}{|l|}{ Condition } \\
\hline & & Aggression & Politeness & $\begin{array}{l}\text { Awareness to } \\
\text { legal punish- } \\
\text { ment }\end{array}$ \\
\hline \multirow[t]{2}{*}{ Type I } & 1 & $\begin{array}{l}\text { Mean }=10.14 \% \\
\text { Std }=8.57 \\
t(70)=9.97 * *\end{array}$ & $\begin{array}{l}\text { Mean }=10.57 \% \\
\text { Std }=9.69 \\
t(72)=9.32 * *\end{array}$ & $\begin{array}{l}\text { Mean }=13.89 \% \\
\text { Std }=10.19 \\
t(69)=11.41 * *\end{array}$ \\
\hline & 2 & $\begin{array}{l}\text { Mean }=3.07 \% \\
\text { Std }=5.63 \\
t(70)=4.60 * *\end{array}$ & $\begin{array}{l}\text { Mean }=4.04 \% \\
\text { Std }=6.04 \\
t(72)=5.73 * *\end{array}$ & $\begin{array}{l}\text { Mean }=3.96 \% \\
\text { Std }=5.47 \\
t(69)=6.06^{* *}\end{array}$ \\
\hline \multirow[t]{2}{*}{ Type II } & 1 & $\begin{array}{l}\text { Mean }=8.33 \% \\
\text { Std }=11.25 \\
t(70)=6.32 * *\end{array}$ & $\begin{array}{l}\text { Mean }=3.84 \% \\
\text { Std }=6.48 \\
t(72)=5.06^{* *}\end{array}$ & $\begin{array}{l}\text { Mean }=5.49 \% \\
\text { Std }=7.14 \\
t(69)=6.42 * *\end{array}$ \\
\hline & 2 & $\begin{array}{l}\text { Mean }=5.57 \% \\
\text { Std }=7.01 \\
t(70)=6.70 * *\end{array}$ & $\begin{array}{l}\text { Mean }=3.92 \% \\
\text { Std }=6.02 \\
t(72)=5.56^{* *}\end{array}$ & $\begin{array}{l}\text { Mean }=4.68 \% \\
\text { Std }=6.23 \\
t(69)=6.27 * *\end{array}$ \\
\hline
\end{tabular}

We denote by $* *$ statistical significance at the 0.01 level 
on percentage of participants' conflicting responses, using mind-set (aggression, politeness, or awareness to legal punishment) as a between-participant variable. For questionnaire 1, mind-set had a significant effect on the occurrence of conflicts of type $\mathrm{I}(F(2,138)=3.53, \mathrm{p}=0.03$, partial $\left.\eta^{2}=0.05\right)$ and on the occurrence of conflicts of type II $(F$ $(1.81,124.63)=5.46, p=0.007$, partial $\left.\eta^{2}=0.07\right)$. (For questionnaire 2, no significant effect of mind-set on conflict occurrence was found). Thus, the results showed that conflicts between ethical and legal judgments depend on consumers' mind-sets.

\section{Uncertainty in Participants' Responses}

As in Experiment 1, to quantify participants' uncertainty, we extracted for each experimental condition the percentage of items for which participants chose the answer "Do not know" or "Do not have an opinion" (3 on Likert scale). We then carried out $t$-tests comparing these percentages to zero. The results are presented in Table 5. Answering questionnaire 1, participants chose the answer ' 3 ' for legal judgments in $21.07 \%-23.56 \%$ of the items, and for ethical judgments in $16.86-19.61 \%$ of the items. These results were significantly different from zero.

\section{Comparison Between the Results of Experiments 1 and 2}

As consumers' mind-sets were not manipulated in Experiment 1, with respect to this variable, Experiment 1 can be considered a control group. Analysis, comparing the means of participants' ethical and legal judgments obtained in each condition of Experiment 2 to those obtained in Experiment 1 , revealed that ethical judgments in the aggression condition $($ mean $=2.75$, std $=1.43)$ was significantly greater than in Experiment $1($ mean $=2.34$, std $=1.31 ; t(1774)=10.48$; $p<0.01)$. Although legal judgments showed a similar tendency (aggression condition: mean $=2.85$, $\mathrm{std}=1.52$; experiment 1 : mean $=2.76$, std $=1.49$ ), the effect was insignificant $(p=0.065)$. No other significant differences were found.

\section{Summary of the Results}

In two experiments, we examined the strength of the association between consumers' ethical and legal judgments, the prevalence of conflicts between them, and their dependence on activity and mind-sets. Consistently with studies emphasizing the similarities between ethicality and legality (Kohlberg 1981; La Torre 2010; Vitell and Muncy 1992), we found significant, positive relations between ethical and legal judgments. This result was robust over all examined mind-sets. Thus, the study supported hypothesis H1.

In line with previous research (Vitell 2003; Vitell and Paolillo 2003), activity was found to affect ethical judgments. Activity had a significant effect on legal judgments, too, although this effect depended on participants' mind-set and was less consistent than the effect of activity on ethical judgments. Therefore, the results supported hypothesis $\mathrm{H} 2 \mathrm{a}$ and $\mathrm{H} 2 \mathrm{~b}$. Activity was found also to significantly affect the occurrence of conflicts between ethical and legal judgments.

Consumers' mind-sets affected their ethical judgments significantly: consistently with previous studies (Tsalikis 2015), participants, in whom aggression was induced, exhibited lower sensitivity to ethical issues than participants in all other conditions. Furthermore, mind-set significantly affected legal judgments. When politeness mind-set was induced in participants, their legal judgments were significantly lower than when they were induced with aggression or awareness to legal punishment. Therefore, in accord with mind-set research (Xu and Wyer 2007), our results supported hypotheses $\mathrm{H} 3 \mathrm{a}$ and $\mathrm{H} 3 \mathrm{~b}$ and emphasized the susceptibility of legal judgments to human judgment biases. However, mind-set had a weaker influence on legal judgments than on ethical judgments. Finally, participants' mind-sets
Table 5 Percentage of participants' responses, which were three ("Do not have an opinion" or "Do not know"), for each questionnaire, and the results of $t$-tests, comparing them to zero

\begin{tabular}{|c|c|c|c|c|}
\hline \multirow[t]{2}{*}{ Measure } & \multirow{2}{*}{$\begin{array}{l}\text { Question- } \\
\text { naire }\end{array}$} & \multicolumn{3}{|l|}{ Condition } \\
\hline & & Aggression & Politeness & $\begin{array}{l}\text { Awareness to } \\
\text { legal punish- } \\
\text { ment }\end{array}$ \\
\hline \multirow[t]{2}{*}{ Percentage of legal judgments } & 1 & $\begin{array}{l}21.07 \% \\
t(70)=14.04 * *\end{array}$ & $\begin{array}{l}23.56 \% \\
t(72)=13.99 * *\end{array}$ & $\begin{array}{l}21.54 \% \\
t(69)=14.91 * *\end{array}$ \\
\hline & 2 & $\begin{array}{l}11.59 \% \\
t(70)=9.40 * *\end{array}$ & $\begin{array}{l}15.57 \% \\
t(72)=10.46^{* *}\end{array}$ & $\begin{array}{l}14.03 \% \\
t(69)=9.63 * *\end{array}$ \\
\hline \multirow[t]{2}{*}{ Percentage of ethical judgments } & 1 & $\begin{array}{l}19.61 \% \\
t(70)=12.67 * *\end{array}$ & $\begin{array}{l}19.45 \% \\
t(72)=10.81 * *\end{array}$ & $\begin{array}{l}16.86 \% \\
t(69)=14.16^{* *}\end{array}$ \\
\hline & 2 & $\begin{array}{l}14.79 \% \\
t(70)=11.12 * *\end{array}$ & $\begin{array}{l}12.45 \% \\
t(72)=8.99 * *\end{array}$ & $\begin{array}{l}13.38 \% \\
t(69)=12.99 * *\end{array}$ \\
\hline
\end{tabular}

**Denotes statistical significance at the 0.01 level 
affected the occurrence of conflicts between ethical and legal judgments.

Our results reveal that conflicts between ethical and legal judgments are prevalent. In addition, consumers choose the answer "Do not know" or "Do not have an opinion" in a considerable proportion of the presented scenarios. Although, to a certain extent, this result may reflect participants' response biases (Randall and Fernandes 1991), it shows that consumers are often indecisive in their ethical and legal judgments. The variance in consumers' answers is considerable, revealing disagreements between individuals' judgments.

Finally, our findings suggest that there is an asymmetry between the effect of positive and negative mind-sets on consumers' judgments: the results do not provide evidence of an increase in sensitivity to ethical issues when politeness or awareness to legal punishment is induced (compared to the results of Experiment 1). However, when aggression is induced in consumers, their sensitivity to ethical issues decreases.

\section{Conclusion}

\section{Discussion}

Criminology theories have proposed that people's legal and moral judgments have central roles in guiding their behavior (Antonaccio et al. 2017; Wikström 2006; Wikström et al. 2011). Nevertheless, neither consumers' legal judgments, nor the similarities and discrepancies between their legal and ethical judgments has been studied. This study provides insights into the way consumers judge morally-questionable behaviors. It portrays individuals' ethical and legal judgments as dynamically-changing and subjective. Furthermore, it depicts the law as a construct which is often inaccessible for consumers or in conflict with their ethical perceptions.

The dynamical nature of consumers' ethical and legal judgments is reflected through their dependence on consumers' mind-sets. People, in whom aggression mind-set is induced, consider morally-questionable behaviors to be more ethical and legal than those in whom politeness mind-set is induced. As mind-sets dynamically change, ethical and legal judgments change, too.

The subjectivity of ethical and legal judgments is exhibited through the considerable variability of consumers' responses. Different people understand the notions of legality and ethicality in different ways.

Finally, consumers are unable to provide legal and ethical judgments of many every-day consumers' behaviors. When they can make judgments, there are often conflicts between their ethical and legal judgments. Therefore, the results highlight the differences between consumers' perceptions of the law and their personal ethical principles.

\section{Business Applications}

This study suggests three methods for reducing consumers' engagement in illegal and unethical practices. In line with stakeholder theory (Crane and Ruebottom 2011; Freeman et al. 2010), we analyze the effects of these methods on investors, consumers, employees, competitors, and governments. First, our study demonstrates that consumers are often unable to make legal and ethical judgments in a range of different industry settings, including retail, e-commerce, hospitality, online media, insurance and public service. Thus, in accord with previous research (Freestone and Mitchell 2004), it suggests that decreasing consumers' engagement in illegal practices may be achieved by enhancing their ethical and legal knowledge. A special educational effort could address situations where ethical and legal judgments are unclear. Examples of morally-questionable behaviors affecting different industry sectors and suggested educational initiatives, aimed at inhibiting them, are presented in Table 6. Ethical and legal educational programs could be developed and administrated by governments and firms. They are likely to enhance consumers' behavior and thus increase firms' and investors' returns. Furthermore, as it has been shown that consumers' dysfunctional behavior affects both customer-contact employees and other consumers (Harris and Reynolds 2003), ethical and legal education

Table 6 Examples of consumers' morally-questionable behaviors in different industry sectors (Muncy and Vitell 1992) and suggestions of educational methods, aimed at inhibiting these behaviors

\begin{tabular}{|c|c|c|c|c|c|}
\hline Industry sector & Retail & Hospitality & Online media & Insurance & Public service \\
\hline $\begin{array}{l}\text { Example of consum- } \\
\text { ers' morally-ques- } \\
\text { tionable behavior in } \\
\text { the sector }\end{array}$ & $\begin{array}{l}\text { Observing someone } \\
\text { shoplifting and } \\
\text { ignoring it }\end{array}$ & $\begin{array}{l}\text { Not saying anything } \\
\text { when the waitress } \\
\text { miscalculates the bill } \\
\text { in your favor }\end{array}$ & $\begin{array}{l}\text { Downloading } \\
\text { movie files from } \\
\text { the Internet for } \\
\text { free }\end{array}$ & $\begin{array}{l}\text { Reporting a lost item } \\
\text { as "stolen" to an } \\
\text { insurance company } \\
\text { to collect the money }\end{array}$ & $\begin{array}{l}\text { Stretching the truth on } \\
\text { an income tax return }\end{array}$ \\
\hline $\begin{array}{l}\text { Suggested educational } \\
\text { initiative, aimed at } \\
\text { inhibiting consum- } \\
\text { ers' behavior }\end{array}$ & Sign-posting in store & $\begin{array}{l}\text { Request to report } \\
\text { errors on bills }\end{array}$ & $\begin{array}{l}\text { Coordinated mar- } \\
\text { keting campaign } \\
\text { against content } \\
\text { piracy }\end{array}$ & $\begin{array}{l}\text { Coordinated market- } \\
\text { ing campaign against } \\
\text { insurance fraud }\end{array}$ & $\begin{array}{l}\text { Information about the } \\
\text { risks of tax evasion } \\
\text { on income tax return } \\
\text { sheet }\end{array}$ \\
\hline
\end{tabular}


programs are likely to improve employees' well-being and consumers' shopping experience. In addition, ethics education could improve the moral efficacy, moral meaningfulness, and moral courage of consumers (May et al. 2014). Educational initiatives, implemented by specific firms, may provide them with advantages over their competitors.

Second, our study reveals that consumers frequently experience conflicts between their ethical and legal judgments. A proportion of consumers may choose to behave according to their ethical judgment rather than their legal judgment. Thus, this study suggests that adopting realistic business models, which take into account conflicts between consumers' ethical and legal judgments, may be more beneficial for firms than legal education programs. Realistic business models have already been implemented in the music industry. The music industry has incurred great losses due to consumers' illegal file sharing and downloading. However, it has been shown that online streaming firms have a positive effect on the revenues of the music industry (Wlömert and Papies 2016). The use of realistic business models, which acknowledge consumers' judgments, does not require any special governmental intervention. Firms adopting them can provide consumers with attractive services, which could make illegal behavior seem unnecessary. Thus, the use of realistic business models may increase firm and investors' revenues and improve employees' well-being. Adopting realistic business models may provide firms with advantages over their competitors.

Finally, our findings emphasize the impact of consumers' mind-sets on their judgments. Aggression mind-set, activated merely by a word unscrambling task, is sufficient to reduce participants' sensitivity to ethical issues significantly in comparison to politeness and awareness to legal punishment mind-sets. Specifically, our results suggest that reducing consumers' aggression levels may discourage consumers' morally-questionable behavior at service places more than emphasizing legal punishments. To a certain extent, that may be achieved in service places by changing their atmosphere. For instance, it has been established that certain types of music reduce customers' aggression (Niven 2015). Mind-set solutions do not require governmental involvement. They may improve the well-being of customercontact employees, consumers' shopping experience (Harris and Reynolds 2003), and endow firms with advantages over their competitors.

\section{Limitations and Directions for Further Research}

This study supports our key hypotheses. However, it has a few limitations, suggesting avenues for future research. First, mind-sets have been induced in this study using priming procedures. Although it has been shown that prime effects and prime awareness are independent (Francken et al. 2011), participants' awareness to the priming procedure might have interacted with their judgments. Therefore, we consider it worthwhile to continue exploring the way consumers make judgments using other research methods.

Second, as a first study on consumers' legal perceptions, it focused on the relationship between consumers' ethical and legal judgments. However, we consider it important to relate our results to consumers' behavior. Research has revealed that certain variables, including ethical care, the willingness to sacrifice, and ethical behavior planning, mediate between consumers' ethical perceptions and behavior (Carrington et al. 2014; Hassan et al. 2016; Shaw et al. 2016). The way consumers justify unethical behavior has been explained by moral disengagement theories (see, e.g., Egan et al. 2015). Of special interest could be a study examining the justification for possible discrepancies between consumers' legal judgments and behavior ("legal disengagement").

Third, studies have demonstrated that a proportion of consumers experience intense conflicts, which could lead to moral anxiety (Carrington et al. 2015). This study raises the question how consumers resolve conflicts between their ethical and legal judgments. Future research could examine this question.

Fourth, in line with previous studies (Ikegami 1993; Tsalikis 2015), our results highlight the asymmetric nature of the effect of mind-sets on judgments. Consumers, who are primed with aggression mind-set, exhibit a decrease in their sensitivity to ethical issues compared to that of consumers in whom no mind-set is induced. However, priming people with politeness or raising their awareness to legal punishment does not increase their sensitivity to ethics. This asymmetric effect may be the result of the way people process information. It has been demonstrated that people process bad information more thoroughly than they process good information (Baumeister et al. 2001). Future studies could explore the reasons for the asymmetry between the effects of positive and negative mind-sets on consumer ethical and legal judgments. We consider it especially beneficial to find ways to increase consumers' sensitivity to ethical and legal issues.

Finally, our study suggests three methods for dealing with consumers' morally-questionable behaviors: educational programs, adopting business models which take into account consumers' ethical and legal judgments, and developing service place atmosphere which reduces consumers' aggression. We hope that this study would lead to further research, examining the effectiveness of these methods and their effects on firm stakeholders.

Acknowledgements The data described in this study was collected by students of the BSc/MSci Management Science program at the School of Management, University College London. We would like to thank Stephen Todd, the program director, for his support. We would like to thank each of the students of the Management Science program 
for their valuable contribution: Ang Pik, Belahrach Azad, Betlen Borbala, Birkle Patrik, Bui Trung, Burvin Alesia, Carter Daniel, Chen Jaime, Chen Shujun, Cheng Feiyang, Choempraphai Pimjitta, Chou Ka, Cristian Calin, Davila Nicole, De Klopstein Charlotte, Egido Maestre Beatriz, Eibl Richard, Fairhead Emma, Ferreira Margarida, Gjerstad Helena, Guan Jia, Gutgutia Udyat, Ho Xin, Jehenne Alix, Kaur D/O Harjinder Singh Simranpal, Khamin Gleb, Lam Sze, Lao Kei, Leung Wan, Leven Laetitia, Martynova Iuliia, Arzumanyan Artem, Masood Fahad, Milanovic Michiel, Monteza Peter, Nicholson Edward, Nie Yajing, Nouri Salar, Olaru Ana-Maria, Opaswongkarn Virin, Peirs Alice, Pesci Federico, Remy De Cournon Hadrien, Sekkat Amine, Smith Laurence, Steshenko Yelyzaveta, Suprano Anthony, Superfin Nicole, Turczi Adam, Verkade Joanna, Voege Niklas, Wong Amy, Ye Yongxin, Zaghouani Fares, Zhao Jiaqiao, Zhu Katja.

\section{Compliance with Ethical Standards}

Conflict of interest All the authors declared that they have no conflict of interest

Ethical Approval All procedures performed in studies involving human participants were in accordance with the ethical standards of the institutional research committee and the Code of Ethics and Conduct of the British Psychological Society.

Informed Consent Informed consent was obtained from all individual participants included in the study.

Open Access This article is distributed under the terms of the Creative Commons Attribution 4.0 International License (http://creativeco mmons.org/licenses/by/4.0/), which permits unrestricted use, distribution, and reproduction in any medium, provided you give appropriate credit to the original author(s) and the source, provide a link to the Creative Commons license, and indicate if changes were made.

\section{Appendix A: Theoretical Contribution to Moral Psychology and Legal Philosophy}

Major streams in moral psychology have explored different aspects of moral judgments: the 'intuitive lawyer' approach has examined the way people attribute moral responsibility, whereas the 'person as moralist' approach has investigated the effect of the characteristics of the decision makers on their moral judgments (Alicke et al. 2015). By exploring the interactions between activity (which is related to responsibility attribution) and mind-sets (which characterize the decision-maker), we link the 'intuitive lawyer' stream with the 'person as moralist' stream. Moreover, despite the 'intuitive lawyer' metaphor, moral psychology has not examined people's legal judgments. Here, we conceptualize legal decision-making as judgment under uncertainty (Tversky and Kahneman 1974) and show that it is subject to human judgmental biases, including dependence on mind-sets.

Legal philosophers have debated what distinguishes law from social norms or habits. It has been suggested that to classify a rule as a law, one should adopt the perception of those who follow and accept it as a law: "For the understanding of this [...] what is needed is a 'hermeneutic' method which involves portraying rule-governed behavior as it appears to its participants" (Hart 2012, p. 13). According to this perception, a rule is a part of the legal system if people acknowledge that it is indeed a law by using "normative terminology of 'ought', 'must', and 'should', 'right' and 'wrong"' (Hart 1994, p. 57), similarly to the way they would accept the rules of chess. It has been argued that "the internal aspect of rules may be simply illustrated from the rules of any game. Chess players do not merely have similar habits of moving the Queen [...] they have a reflective critical attitude to this pattern of behaviour [...] These views are manifested in [...] the acknowledgement of the legitimacy of such criticism" (Hart 1994, pp. 56-57). A second theory has proposed that to analyze the legal system, one should assume the point of view of those who consider it legal and moral: "if there is a point of view in which legal obligation is treated as at least presumptively a moral obligation [...], then such a viewpoint will constitute the central case of the legal viewpoint" (Finnis 2011, pp. 14-15). However, this study shows that people's judgment depends on their mind-sets and exhibits high variance. Therefore, to assume another's point of view, one should determine whose point of view one assumes and in which mind-set this person is. That makes the suggested process difficult to define. Furthermore, we show that legal judgment is subjective, context-dependent, and many times inconclusive. Therefore, it is qualitatively different from the judgment of game rules. Finally, it is often in conflict with people's ethical judgment. Therefore, our results do not support theories suggesting that law can be defined by people's judgments. However, other philosophers have argued that the validity of law stems from the existence of a legal system which is in force in a certain country (Raz 2012, pp. 150-152). Our results suggest that this approach could be adopted to distinguish between laws and social norms.

\section{Appendix B}

Sentence completion task of the awareness to legal punishment condition.

Please circle four of the five words in order to make a complete sentence

1. was verdict severe given usually

2. arrest she under is always

3. to normally returned he court

4. jail rapidly they in were

5. fine the was they high

6. slowly sentence decided jail was

7. guilty she found sometimes was

8. the strict usually judge was 
9. is normally the unhappy jury

10. prison faced sentences they often

11. always judge the appeals refused

12. long her trial was his

13. lawyer them his was upset

14. he not were charges dismissed

\section{Endnote}

The terms 'ethics' and 'morality' are often used as synonyms, although the term 'ethics' may express a specialized area of morality (see, e.g., Downie 2005).

\section{References}

Alicke, M. D., Mandel, D. R., Hilton, D. J., Gerstenberg, T., \& Lagnado, D. A. (2015). Causal conceptions in social explanation and moral evaluation. Perspectives on Psychological Science, 10(6), 790-812.

Antonaccio, O., Botchkovar, E. V., \& Hughes, L. A. (2017). Ecological determinants of situated choice in situational action theory. Journal of Research in Crime and Delinquency, 54(2), 208-243.

Asscher, J. (2007). Killing and letting die: The similarity criterion. Journal of Applied Philosophy, 24(3), 271-282.

Bamfield, J. (2004). Shrinkage, shoplifting and the cost of retail crime in Europe: A cross-sectional analysis of major retailers in 16 European countries. International Journal of Retail \& Distribution Management, 32(5), 235-241.

Bargh, J. A., Chen, M., \& Burrows, L. (1996). Automaticity of social behaviour: Direct effects of trait construct and stereotype activation on action. Journal of Personality and Social Psychology, $71,230-244$.

Barry, C., Lindauer, M., \& Øverland, G. (2014). Doing, allowing, and enabling harm: An empirical investigation. In J. Knobe, T. Lombrozo \& S. Nichols (Eds.), Oxford studies in experimental philosophy (Oxford studies in experimental philosophy, Chap. 4). Oxford: Oxford University Press. https://doi.org/10.1093/ acprof:oso/9780198718765.001.0001.

Baumeister, R. F., Bratslavsky, E., Finkenauer, C., \& Vohs, K. D. (2001). Bad is stronger than good. Review of General Psychology, 5(4), 323-370.

Bennett, J. (2003). The act itself. Oxford: Clarendon. https://doi. org/10.1093/019823791X.001.0001.

Blanco, C., Grant, J., Petry, N. M., Simpson, B. H., Alegria, A., Liu, S. M., \& Hasin, D. (2008). Prevalence and correlates of shoplifting in the United States: Results from the national epidemiologic survey on alcohol and related conditions (NESARC). The American journal of psychiatry, 165(7), 905-913.

Bradley, B., \& Stocker, M. (2005). "Doing and allowing" and doing and allowing. Ethics, 115(4), 799-808.

Brady, N., \& Hart, D. (2007). An exploration into the developmental psychology of ethical theory with implications for business practice and pedagogy. Journal of Business Ethics, 76(4), 397-412.

Callan, M., Harvey, A., Dawtry, R., \& Sutton, R. (2013). Through the looking glass: Focusing on long-term goals increases immanent justice reasoning. British Journal of Social Psychology, $52,377-385$.
Carlson, M., Marcus-Newhall, A., \& Miller, N. (1990). Effects of situational aggression cues: A quantitative review. Journal of Personality and Social Psychology, 58(4), 622-633.

Carrington, M. J., Neville, B., \& Canniford, R. (2015). Unmanageable multiplicity: Consumer transformation towards moral self coherence. European Journal of Marketing, 49(7/8), $1300-1325$.

Carrington, M. J., Neville, B. A., \& Whitwell, G. J. (2014). Lost in translation: Exploring the ethical consumer intention-behavior gap. Journal of Business Research, 67(1), 2759-2767.

Cheng, J. S., Ottati, V. C., \& Price, E. D. (2013). The arousal model of moral condemnation. Journal of Experimental Social Psychology, 49(6), 1012-1018.

Cook, R. D. (1977). Detection of influential observations in linear regression. Technometrics, 19, 15-18.

Crane, A., \& Ruebottom, T. (2011). Stakeholder theory and social identity: Rethinking stakeholder identification. Journal of Business Ethics, 102(Supplement 1), 77-87.

Cushman, F., Knobe, J., \& Sinnott-Armstrong, W. (2008). Moral appraisals affect doing/allowing judgments. Cognition, 108(1), 281-289.

Daunt, K. L., \& Harris, L. C. (2012). Motives of dysfunctional customer behavior: An empirical study. Journal of Services Marketing, 26(4), 293-308.

Downie, R. S. (2005). Ethics and morality. In T. Honderich (Ed.), The Oxford companion to philosophy. Oxford: Oxford University Press.

Egan, V., Hughes, N., \& Palmer, E. J. (2015). Moral disengagement, the dark triad, and unethical consumer attitudes. Personality and Individual Differences, 76, 123-128.

Finnis, J. (2011). Natural law and natural rights, Clarendon Law Series (2 edn.). New York: Oxford University Press.

Francken, J., van Gaal, S., \& de Lange, F. (2011). Immediate and long-term priming effects are independent of prime awareness. Consciousness and Cognition, 20(4), 1793-1800.

Freeman, R. E., Harrison, J. S., Wicks, A. C., Parmar, B. L., \& de Colle, S. (2010). Stakeholder theory: The state of the art. Cambridge: Cambridge University Press.

Freestone, O., \& Mitchell, V. (2004). Generation Y attitudes towards e-ethics and internet-related misbehaviours. Journal of Business Ethics, 54(2), 121-128.

Gopal, R. D., \& Gupta, A. (2010). Trading higher software piracy for higher profits: The case of phantom piracy. Management Science, 56(11), 1946-1962.

Harris, L. C. (2008). Fraudulent return proclivity: An empirical analysis. Journal of Retailing, 84(4), 461-476.

Harris, L. C., \& Reynolds, K. L. (2003). The consequences of dysfunctional customer behavior. Journal of Service Research, 6(2), 144-161.

Hart, H. (1994). The concept of law (Second edition with a postscript edited by P. A. Bulloch \& J. Raz) Clarendon Press, Oxford University press: New York.

Hart, H. L. A. (2012). Essays in jurisprudence and philosophy. Oxford: Clarendon. https://doi.org/10.1093/acprof:oso/97801 98253884.001.0001.

Hassan, L., Shiu, M., \& Shaw, E. (2016). Who says there is an intention-behaviour gap? Assessing the empirical evidence of an intention-behaviour gap in ethical consumption. Journal of Business Ethics, 136(2), 219-236.

Helwig, C. C., Zelazo, P. D., \& Wilson, M. (2001). Children's judgments of psychological harm in normal and noncanonical situations. Child Development, 72, 66-81.

Husak, D. N. (2010). The philosophy of criminal law: Selected essays. Oxford: Oxford University Press. 
Ikegami, T. (1993). Positive-negative asymmetry of priming effects on impression formation. European Journal of Social Psychology, 23(1), 1-16.

Janiszewski, C., \& Wyer, R. S. (2014). Content and process priming: A review. Journal of Consumer Psychology, 24(1), 96-118.

Kohlberg, L. (1981). The philosophy of moral development: Moral stages and the idea of justice. San Francisco: Harper \& Row.

Kos Koklic, M., Kukar-Kinney, M., \& Vida, I. (2016). Three-level mechanism of consumer digital piracy: Development and crosscultural validation. Journal of Business Ethics, 134(1), 15-27.

La Torre, M. (2010). Law as institution. Dordrecht: Springer.

Libby, B., \& Agnello, V. (2000). Ethical decision making and the law. Journal of Business Ethics, 26(3), 223-232.

May, D., Luth, M., \& Schwoerer, C. (2014). The influence of business ethics education on moral efficacy, moral meaningfulness, and moral courage: A quasi-experimental study. Journal of Business Ethics, 124(1), 67-80.

Muncy, J. A., \& Vitell, S. J. (1992). Consumer ethics: An investigation of the ethical beliefs of the final consumer. Journal of Business Research, 24(4), 297-311.

Niven, K. (2015). Can music with prosocial lyrics heal the working world? A field intervention in a call center. Journal of Applied Social Psychology, 45(3), 132-138.

Pearce, J. A. (2013). Using social identity theory to predict managers' emphases on ethical and legal values in judging business issues. Journal of Business Ethics, 112(3), 497-514.

Pizarro, D. (2000). Nothing more than feelings? The role of emotions in moral judgment. Journal for the Theory of Social Behaviour, 30(4), 355-375.

Pleasence, P., \& Balmer, N. J. (2012). Ignorance in bliss: Modeling knowledge of rights in marriage and cohabitation. Law \& Society Review, 46(2), 297-333.

Powell, N. L., Derbyshire, S. W. G., \& Guttentag, R. E. (2012). Biases in children's and adults' moral judgments. Journal of Experimental Child Psychology, 113(1), 186-193.

Preston-Shoot, M., \& Mckimm, J. (2013). Exploring UK medical and social work students' legal literacy: Comparisons, contrasts and implications. Health \& Social Care in the Community, 21(3), 271-282.

Rallapalli, K. C., Vitell, S. J., Wiebe, F. A., \& Barnes, J. H. (1994). Consumer ethical beliefs and personality traits: An exploratory analysis. Journal of Business Ethics, 13(7), 487-495.

Randall, D. M., \& Fernandes, M. F. (1991). The social desirability response bias in ethics research. Journal of Business Ethics, 10, 805-817.

Rawls, J. (1999). A theory of Justice, Revised edition. Cambridge: The Belkand Press of Harvard University Press.

Raz, J. (2012). The authority of law: Essays on law and morality. https ://doi.org/10.1093/acprof:oso/9780198253457.001.0001.

Reynolds, K. L., \& Harris, L. C. (2005). When service failure is not service failure: An exploration of the forms and motives of "illegitimate" customer complaining. Journal of Services Marketing, 19(5), 321-335.

Reynolds, K. L., \& Harris, L. C. (2009). Dysfunctional customer behavior severity: An empirical examination. Journal of Retailing, 85(3), 321-335.

Robinson, P., \& Darley, J. (2004). Does criminal law deter? A behavioural science investigation. Oxford Journal of Legal Studies, 24(2), 173-205.
Shaw, D., McMaster, R., \& Newholm, T. (2016). Care and commitment in ethical consumption: An exploration of the 'attitude-behaviour gap'. Journal of Business Ethics, 136(2), 251-265.

Simmons, J., Nelson, L. D., \& Simonsohn, U. (2013). Life after p-hacking. Advances in Consumer Research, 41, 775.

Sloman, S., Barbey, A., \& Hotaling, J. (2009). A causal model theory of the meaning of cause, enable, and prevent. Cognitive Science, $33(1), 21-50$.

Smetana, J. G. (1985). Preschool children's conceptions of transgressions. Developmental Psychology, 21, 715-724.

Todorov, A., \& Bargh, J. A. (2002). Automatic sources of aggression. Aggression and Violent Behavior, 7(1), 53-68.

Tsalikis, J. (2015). The effects of priming on business ethical perceptions: A comparison between two cultures. Journal of Business Ethics, 131(3), 567-575.

Tversky, A., \& Kahneman, D. (1973). Availability: A heuristic for judging frequency and probability. Cognitive Psychology, 5(2), 207-232.

Tversky, A., \& Kahneman, D. (1974). Judgment under uncertainty: Heuristics and biases. Science, 185(4157), 1124-1131.

Ullmann-Margalit, E. (1977). The emergence of norms. Oxford: Clarendon Press.

Vitell, S. (2003). Consumer ethics research: Review, synthesis and suggestions for the future. Journal of Business Ethics, 43(1), 33-47.

Vitell, S., King, R., Howie, K., Toti, J.-F., Albert, L., Hidalgo, E., \& Yacout, O. (2016). Spirituality, moral identity, and consumer ethics: A multi-cultural study. Journal of Business Ethics, 139(1), 147-160.

Vitell, S., \& Muncy, J. (1992). Consumer ethics: An empirical investigation of factors influencing ethical judgments of the final consumer. Journal of Business Ethics, 11(8), 585-597.

Vitell, S., Singhapakdi, A., \& Thomas, J. (2001). Consumer ethics: An application and empirical testing of the Hunt-Vitell theory of ethics. Journal of Consumer Marketing, 18(2), 153-178.

Vitell, S. J., \& Paolillo, J. G. P. (2003). Consumer ethics: The role of religiosity. Journal of Business Ethics, 46, 151-162.

Walker, A., Smither, G., \& DeBode, J. (2012). The effects of religiosity on ethical judgments. Journal of Business Ethics, 106(4), 437-452.

Wikström, P. O. H. (2006). Individuals, settings, and acts of crime: Situational mechanisms and the explanation of crime. In P. O. H. Wikström \& R. J. Sampson (Eds.), The explanation of crime: Contexts, mechanisms, and development (pp. 61-107). Cambridge: Cambridge University Press.

Wikström, P. O. H., Tseloni, A., \& Karlis, D. (2011). Do people comply with the law because they fear getting caught? European Journal of Criminology, 8(5), 401-420.

Wlömert, N., \& Papies, D. (2016). On-demand streaming services and music industry revenues-Insights from Spotify's market entry. International Journal of Research in Marketing, 33(2), 314-327.

Xu, A. J., \& Wyer, R. S. (2007). The effect of mind-sets on consumer decision strategies. Journal of Consumer Research, 34(4), $556-566$.

Publisher's Note Springer Nature remains neutral with regard to jurisdictional claims in published maps and institutional affiliations. 